\title{
Aging of the Population, Clinical Pharmacy Services, and Interdisciplinary Cooperation in the Optimization of Pharmacotherapy in Older Patients
}

\author{
Daniela Fialová $^{1,2,3}$ (D) Franciska Desplenter $^{4}$
}

Published online: 24 March 2016

(C) Springer International Publishing Switzerland 2016

In the last few decades a significant trend in the prolongation of life-expectancy has been observed in many countries. This trend can be celebrated as one of humanity's major achievements [1]; however, as a consequence, it has also contributed to the exponential growth in the proportion of older adults in the world population and to a higher economic burden on healthcare and social systems [2].

The United Nationś Second World Assembly on Ageing summarized in the international report for member countries in 2002 that the number of persons aged 60 years and older will substantially increase from 600 million to almost 2 billion by the year 2050, and the proportion of seniors in the world population will more than double-from 10 to $21 \%$

Daniela Fialová: Chair of the Scientific Committee for 42nd European Symposium on Clinical Pharmacy "Implementation of Clinical

Pharmacy Practice: Research, Education and Management" (16-18th October, 2013, Prague, Czech Republic). Franciska Desplenter: Past President of the European Society of Clinical Pharmacy (ESCP).

Daniela Fialová

daniela.fialova@faf.cuni.cz

1 University Educational Centre in Clinical Pharmacy, Faculty of Pharmacy in Hradec Králové, Charles University in Prague, Heyrovského 1203, 50005 Hradec Králové, Czech Republic

2 Department of Social and Clinical Pharmacy, Faculty of Pharmacy in Hradec Králové, Charles University in Prague, Heyrovského 1203, 50005 Hradec Králové, Czech Republic

3 Department of Geriatrics and Gerontology, 1st Faculty of Medicine, Charles University in Prague, Londýnská 15, 12000 Prague 2, Czech Republic

4 Department of Clinical Pharmacology and Pharmacotherapy, K.U. Leuven, Campus Kortenberg, Leuvensesteenweg 517, B-3070 Kortenberg, Belgium
[1]. In some countries, such as in Eastern Europe, demographic statistics predict an increase in the proportion of older adults of up to $30 \%$ and more by 2050 , e.g., in Slovenia $33.7 \%$, Bulgaria $31.1 \%$, the Czech Republic and Poland $30.6 \%$ [2]. Within this old age group, the proportion of the "oldest old" (individuals 80 years and older) will be rising the most rapidly. According to demographic estimations, the number of the "oldest old" will nearly quadruple in the world population, up to 400 million by 2050 [1]. In the Czech Republic, it will increase two to three times, from 18 to $48 \%$, between the years 2000 and 2065 [3]. In developing countries, the proportion of seniors in the whole population will nearly quadruple in the next 50 years [1].

Among the other consequences of exponential aging, dramatic changes in the labor market can be expected. It is estimated that total expenditures for care and medications will rise, but the proportion of persons in the productive age range will decrease. Using United Nationś prognoses, the "old-age dependency ratio" (ratio of the population aged $65+$ per 100 persons to those in the productive age of 15-64 years) will increase in the majority of countries from $12-32 \%$ in 2015 to $45-61 \%$ in 2100 . These statistics apply to the United States, Canada, Belgium, the UK and Sweden. In some countries, the old-age dependency ratio will reach up to $80-83 \%$ by the year 2100 (e.g., in Poland and Germany) [1]. The lower proportion of persons in the productive age will be followed by reduced numbers of informal and formal caregivers. The lack of nurses is already significant in many countries.

It is well documented that older people consume the highest proportion of costs for medications-approximately $30 \%$ of overall costs $[4,14]$-and this high consumption relates also to multi-morbidity, polypharmacy, irrational prescribing and common misuse of medications. 
According to results of the European project ADHOC (AgeD in Home Care, 5th Framework Programme of the European Commission, 2001-2005, analyses in eight EU countries: Italy, Czech Republic, Denmark, Finland, Iceland, Netherlands, Norway and the UK) [5, 6], $51 \%$ of seniors in home care used six or more medications, and excessive polypharmacy (nine or more medications) was observed in $22.2 \%$ (in the Czech Republic, in $30 \%$ of seniors). Psychotherapy (at least one psychotropic medication) was prescribed to $43.4 \%$ of older adults, with the highest prevalence in Northern European countries (e.g., more than $40 \%$ in Norway and over $60 \%$ in Iceland and Finland). An absence of medication review in the past 6 months was documented in $17.9 \%$ of older home care patients, and $19.8 \%$ of them used potentially inappropriate medications, even when safer and equally effective and accessible alternatives were available on the pharmaceutical market [6].

Higher prevalence of multiple chronic disorders, symptoms and geriatric syndromes (sometimes as a consequence of inappropriate multiple drug therapy) as well as frailty, functional impairment, poor compliance and adverse drug events [7,9] are common in the older population. Adverse drug reactions and drug interactions occur four to seven times more frequently in the geriatric population when compared with middle-aged individuals. The prevalence of adverse drug reactions is documented to be 20-30\% in the 70-79 years age group compared with $3-6 \%$ in the $20-29$ years age group [7-10]. Frequent drugrelated complications result in a higher percentage of acute care admissions (in 6.6-41.3\% of older patients) [11], a higher number of physicianś visits and consequently a significantly greater proportion of total expenditure for drug treatment [11-13]. Total drug-related costs are estimated to be three to four times higher than the direct medication costs [14-16], and the rational use of drugs in the elderly is of major economic and social concern in many countries worldwide.

Particularly the oldest old seniors suffer from more disorders, use more medications and are more frail and dependent than younger individuals. Rational geriatric prescribing depends on a comprehensive knowledge of the pharmacological properties of prescribed drugs, clinical skills and knowledge of efficacy and safety of different medications in individual patients. It represents a challenge, because guidelines are mostly disease specific and often cannot be generalized to complex frail older adults who are using polypharmacy and suffering from multiple, highly individual health problems [12]. Rational use of medicine requires a multidisciplinary approach and the sharing of knowledge and skills to select the best strategy and yield optimal results. With the aging of the population and increasing burden on healthcare professionals, the role of pharmacists in rational geriatric pharmacotherapy will significantly increase, and their involvement in multidisciplinary cooperation will be critically important in different settings of care [10]. Demographic transformation will also open opportunities for geriatric medicine and clinical pharmacy to spread knowledge of geriatrics and rational geriatric pharmacotherapy to other medical and pharmaceutical fields and to support healthier aging (e.g., by reducing excessive morbidity and drug burden in older patients).

The 42nd Symposium on Clinical Pharmacy of the European Society of Clinical Pharmacy, held in 2013 in Prague, Czech Republic [17], highlighted among its main objectives an important dialog on experiences and future directions in the implementation of clinical pharmacy practice in different settings of care and different countries over the coming decades. Clinical pharmacy in geriatrics became one of the core topics represented by a specific symposium. This theme issue of Drugs \& Aging summarizes some of the invited lectures from renowned international experts in clinical pharmacy, medication safety, and geriatrics devoted to the development of clinical pharmacy practice in the United States, some European countries and Australia, and particularly presents selected examples of the development of geriatric clinical pharmacy services in different settings of care. The title of this theme issue is "Clinical Pharmacy Services, Rational Pharmacotherapy and Interdisciplinary Cooperation in the Optimization of Pharmacotherapy in Different Settings of Care". It emphasizes the role of clinical pharmacy services in optimizing pharmacotherapy in the older population, understanding the history of the development of clinical pharmacy services, descriptions of important "successes and failures" in the implementation of clinical pharmacy practice (particularly in acute care, home care, residential care, and community pharmacy practice), the crucial role of medication safety systems in supporting safe medication use, and the importance of the interconnection between individualized older patient care and systematic approaches, ensuring together, medication safety.

The leading article is by Professor Barry Carter from the College of Pharmacy, University of Iowa, Iowa, USA - the Past President of the American College of Clinical Pharmacy (ACCP) [18]. His article entitled "Evolution of Clinical Pharmacy in the USA and Future Directions for Patient Care" comprehensively describes the history of clinical pharmacy services in the United States in both hospital and outpatient settings, key milestones that helped to set up a positive environment for new clinical pharmacy services, and major developments that have shaped the current practice [19]. The second key contribution is the article by Professor Mirko Petrovič, professor of geriatrics at the University of Ghent, Belgium, and an active member 
of the European Union Geriatric Medicine Society (EUGMS) [20]. It summarizes different approaches in the optimization of geriatric pharmacotherapy and the role of multifaceted cooperation among physicians, nurses, and clinical and other pharmacists [21]. It discusses also the fact that despite the many different types of common interventions to optimize drug regimens in older patients (e.g., pharmacist-led medication reviews, educational interventions, computerized decision support systems, comprehensive geriatric assessment, etc.), none of these interventions alone has resulted in a positive impact on health-related outcomes in complex older patients. Only when these interventions have been combined and used within the context of a multidisciplinary team, such positive outcomes have been documented. This contribution strongly emphasizes the importance of multidisciplinary cooperation in the optimization of geriatric pharmacotherapy and the need for additional future collaborative efforts to achieve the best results [21].

Three other articles included in this issue summarize practical experiences with establishing specific clinical pharmacy services and the successful implementation of clinical pharmacy practices in different settings of care, including acute care, home care, residential care and community pharmacy practice. These articles are "Experience with the Implementation of Clinical Pharmacy Services and Processes in a University Hospital in Belgium" [22] by Dr. Annemie Somers, a Chief Clinical Pharmacist at the University Hospital of Ghent, Belgium; "Pharmacist-Led Home Medicines Review and Residential Medication Management Review: The Australian Model" [23] by Professor Tim Chen from the Faculty of Pharmacy, University of Sydney, Australia; and "Development of Clinical Pharmacy in Switzerland: Involvement of Community Pharmacists in Care for Older Patients" [24] by Professor Kurt E. Hersberger from the Department of Pharmaceutical Sciences at the University of Basel, Switzerland, and past President of the Pharmaceutical Care Network of Europe (PCNE) [25]. These contributions describe barriers to and successes in daily clinical practice regarding the implementation of clinical pharmacy services, and practical recommendations. As clinical pharmacy services are in many European countries still novel services, we trust that this theme issue will support their further implementation and will serve as a bridge among different healthcare professionals to the successful development of complex care ensuring individualized geriatric pharmacotherapy.

The closing article of the issue is on the topic "Medication Safety Systems and the Important Role of Pharmacists" [26], and is contributed by Dr. Jeannell M. Mansur, Practice Leader for Medication Safety, Joint Commission International (JCI) [27]. It describes the performance of medication safety systems and provides strategic, yet practical direction for building a medication safety program in a hospital setting. The article also illustrates specific roles of clinical pharmacists in supporting safe medication use in different populations, including the elderly, and in a variety of settings. Because of multiple comorbidities, frequent polypharmacy and medication misuse, the population that will most benefit from expansion of medication safety programs and clinical pharmacy services will be the growing older population. On a broader scale, the development of e-health technologies and the creation of a medication safety system structure will support the benefits from the clinical pharmacist's effort in individualizing medication therapy, ensuring better medication safety.

This theme issue represents selected "fruits" of the current experience on successes and failures in developing clinical pharmacy services in complex older patients in acute care, home care, residential care and community pharmacy practice in different countries across the world. The current President of the ESCP [28], Dr. Markus Lampert from the University of Basel, Switzerland, has added the introduction to this theme issue, in which he has included the wise words of Professor Steve Hudson (professor in memoriam from the Strathclyde University in Edinburgh, Scotland), a prominent mentor and leader of the profession of clinical pharmacy in Europe. The role of clinical pharmacy services and the participation of clinical pharmacists and pharmacists in direct patient care have gone through important changes over past decades and will require further support and transformation in the future, particularly in the development of ideal models of these services for various settings of care and various geriatric populations.

The ESCP as an international organization leading efforts in advancing quality and innovation in clinical pharmacy education, practice and research. It represents a European platform of clinical and other pharmacists interested in clinical pharmacy development (e.g., hospital, community pharmacists) and also other healthcare professionals, researchers and educators with such an interest. In 2014, in Copenhagen, the ESCP updated its vision and mission and emphasized development of clinical pharmacy services for all patients in need through progress in three core areas of clinical pharmacy: education, clinical practice and research. Multidisciplinary cooperation in the development of clinical pharmacy services has always been emphasized and promoted by this society in close collaboration with other societies and professional organizations. Currently, with its membership of 400-500 members from approximately 50 different countries, the ESCP becomes a core leader of clinical pharmacy development in Europe, together with the PCNE. 
This theme issue was prepared in collaboration with different professionals-university teachers of clinical pharmacy and geriatrics, practicing clinical pharmacists and geriatricians, leaders of the medication safety programs, researchers, etc. It also includes contributions and experiences from different countries-Australia, Belgium, Switzerland and the USA. We trust that this issue will give readers inspiration for advancing their own national education, practice and/or research in the field of clinical pharmacy and will emphasize the important development of individualized clinical pharmacy services with a special focus on geriatric patients in different settings of care.

Acknowledgments This theme issue is dedicated to prof. Jiří Vlček from the Faculty of Pharmacy, Charles University, Czech Republicthe President of the 42nd ESCP Symposium on Clinical Pharmacy in Prague who initiated organization of this Symposium and significantly contributed to the development of clinical pharmacy practice in the Czech Republic. It is also dedicated to prof. Steve Hudson (in memoriam) and the European Society of Clinical Pharmacy for longterm effort in development of clinical pharmacy practice in different countries worldwide.

\section{Compliance with ethical standards}

Conflicts of interest Dr. Fialová is supported in her research work by the Charles University program PRVOUK at the Department of Social and Clinical Pharmacy, Faculty of Pharmacy, Charles University in Prague, Czech Republic-PRVOUK P40/FaF UK. She also cooperates with the research network granted by the EU COST Action 1402 "Ageism-interprofessional, multinational perspective" and is financed by this EU COST Action to participate at scientific meetings. Works on this article were supported by both research initiatives-PRVOUK P40/FaF UK and EU COST Action 1402. Dr. Desplenter declares no funding or conflicts of interest relating to this article.

\section{References}

1. United Nations. Report of the Second World Assembly on Ageing. Madrid, Spain, 8-12 April, 2002. [online]. Available at: http://www.un.org/en/ga/search/view_doc.asp?symbol=A/CONF. 197/9. Accessed 11 Feb 2016.

2. Mamolo M, Scherbov S. Population projections for forty-four European countries: the ongoing population ageing. European Demographic Research Papers 2009/2. Vienna Institute of Demography of the Austrian Academy of Sciences: Vienna; 2009. p. 63. [online]. Available at: http://www.oeaw.ac.at/vid/ download/edrp_2_09.pdf. Accessed 16 Feb 2016.

3. Svobodová, K. Analýza 23.3.2012. Demografické stárnutí ČR podle výsledků projekce (Demographic aging of the population according to projection results). Demografie (Demography-in Czech) [online]. ISSN 1801-2914. Available at: http:// demografie.info/?cz_detail_clanku=\&artclID $=824$. Accessed 11 Feb 2016

4. Fialova D. Specifické rysy geriatrické farmakoterapie I-Změna terapeutické hodnoty léků ve stáŕi (Specific features of the geriatric pharmacotherapy I.- Changes in the therapeutic value of medications in the old age- in Czech). Karolinum Publishing, Prague; 2007. p. 90 (ISBN 978-80-246-1353-6).
5. Sørbye LW, Garms-Homolová V, Henrard JC, Jónsson PV, Fialová D, Topinková E, Gambassi G. Shaping home care in Europe: the contribution of the Aged in Home Care project. Maturitas. 2009;62(3):235-42.

6. Fialová D, Topinková E, Gambassi G, For the AdHOC Project Research Group, et al. Potentially inappropriate medication use among elderly home care patients in Europe. JAMA. 2005;293(11):1348-58.

7. Onder G, Liperoti R, Fialova D, for the SHELTER Project, et al. Polypharmacy in nursing home in Europe: results from the SHELTER study. J Gerontol A Biol Sci Med Sci. 2012;67(6): 698-704.

8. Beard K. Adverse reactions as a cause of hospital admission in the aged. Drugs Aging. 1992;2(4):356-67.

9. Fialová D, Onder G. Medication errors in elderly people: contributing factors and future perspectives. Br J Clin Pharmacol. 2009;67(6):641-5.

10. Spinewine A, Fialová D, Byrne S. The role of the pharmacist in optimizing pharmacotherapy in older people. Drugs Aging. 2012;29(6):495-510.

11. Beijer HJ, de Blaey CJ. Hospitalisations caused by adverse drug reactions (ADR): a meta-analysis of observational studies. Phar World Sci. 2002;24(2):46-54.

12. Steinman MA, Hanlon JT. Managing medications in clinically complex elders: "There's got to be a happy medium". JAMA. 2010;304(14):1592-601.

13. Onder G, Liperoti R, Foebel A, et al. Polypharmacy and mortality among nursing home residents with advanced cognitive impairment: results from the SHELTER study. J Am Med Dir Assoc. 2013;14(6):450.e7-12.

14. Johnson JA, Bootman JL. Drug-related morbidity and mortality. A cost-of-illness model. Arch Intern Med. 1995;155(18):1949-56.

15. Bordet R, Gautier S, Le Louet H, Dupuis B, Caron J. Analysis of the direct cost of adverse drug reactions in hospitalised patients. Eur J Clin Pharmacol. 2001;56(12):935-41.

16. Leendertse AJ, Van Den Bemt PM, Poolman JB, Stoker LJ, Egberts AC, Postma MJ. Preventable hospital admissions related to medication (HARM): cost analysis of the HARM study. Value Health. 2011;14(1):34-40.

17. 42nd ESCP Symposium on Clinical Pharmacy: Implementation of Clinical Pharmacy Practice: Research, Education and Management. October 16-18, 2013, Prague, Czech Republic. [online]. Available at: http://www.escp-prague.eu/. Accessed 18 Feb 2016.

18. ACCP-American College of Clinical Pharmacy. [online]. Available at: http://www.accp.com/. Accessed 18 Feb 2016.

19. Carter BL. Evolution of clinical pharmacy in the USA and future directions for patient care. Drugs Aging. 2016. doi:10.1007/ s40266-016-0349-2

20. EUGMS-European Union Geriatric Medicine Society. [online]. Available at: http://www.eugms.org/home.html http://www.accp. com/. Accessed 18 Feb 2016.

21. Petrovič M, Sommers A, Onder G. Optimisation of geriatric pharmacotherapy: role of multifaceted cooperation in the hospital setting. Drugs Aging. 2016. doi:10.1007/s40266-016-0352-7

22. Sommers A. Experience with the implementation of clinical pharmacy services and processes in a university hospital in Belgium. Drugs Aging. 2016. doi:10.1007/s40266-016-0356-3

23. Chen TF. Pharmacist-led home medicines review and residential medication management review: the Australian model. Drugs Aging. 2016. doi:10.1007/s40266-016-0357-2

24. Hersberger KM, Messerli M. Development of clinical pharmacy in Switzerland: involvement of community pharmacists in care for older patients. Drugs Aging. 2016. doi:10.1007/s40266-0160353-6

25. PCNE-Pharmaceutical Care Network of Europe. [online]. Available at: http://www.pcne.org/. Accessed 18 Feb 2016. 
26. Mansur JM. Medication safety systems and the important role of pharmacists. Drugs Aging. 2016. doi:10.1007/s40266-016-0358-1

27. JCI-Joined Commission International. [online]. Available at: http://www.jointcommissioninternational.org/. Accessed 18 Feb 2016.
28. ESCP-European Society of Clinical Pharmacy. [online]. Available at: http://www.escpweb.org/cms/. Accessed 18 Feb 2016. 